\title{
Геодинамика и металлогеническая специализация раннего докембрия Кольского региона
}

\author{
Козлов Н.Е. ${ }^{1}$, Сорохтин Н.О. ${ }^{2}$, Мартынов Е.В. ${ }^{1}$ \\ ${ }^{1}$ Геологический институт КНЦ РАН, Anamumbl,kozlov@geoksc.apatity.ru \\ ${ }^{2}$ Институт океанологии им. П.П. Ширшова РАН, Москва, nsorokhtin@ocean.ru
}

\begin{abstract}
Аннотация. В работе рассмотрены вопросы возможной связи металлогении отдельных раннедокембрийских структур Кольского региона. Показано, что данные о геодинамической эволюции структурновещественных комплексов в архейское время, в сочетании с информацией о том, что специфика вулканизма раннего докембрия могли предопределить своеобразие и уникальность состава продуктов последующих этапов магматизма. Сделан вывод о том, что металлогенический прогноз на основе геодинамических реконструкции представляется перспективным направлением дальнейших исследований. Это тем более важно для раннедокембрийских регионов, поскольку ранее авторами описан и обоснован полициклический и многоступенчатый механизм обогащения континентальной земной коры рудными элементами, который приводит к увеличению концентраций полезных компонентов в рудных залежах от древних комплексов к молодым как в фанерозое, так и в докембрии. В работе подчеркнуто, что углеродистые сланцы Кейвского домена могут быть обогащены нанозолотом в промышленных объемах и наряду с алюминиевым сырьем стать крупной золотоносной провинцией Кольского региона.
\end{abstract}

Ключевые слова: состав, докембрий, геодинамическая эволюция, металлогения.

\section{Geodynamics and metallogenic specialization of the Early Precambrian Kola region}

\author{
Kozlov N.E. ${ }^{1}$, Sorokhtin N.O. ${ }^{2}$, Martynov E.V. ${ }^{1}$ \\ ${ }^{1}$ Geological Institute of the Kola Science Centre RAS, Apatity, kozlov@geoksc.apatity.ru \\ ${ }^{2}$ P.P Shirshov Institute of Oceanology RAS, Moscow,nsorokhtin@ocean.ru
}

\begin{abstract}
This paper highlights a possible metallogenic connection between individual Early Precambrian structures of the Kola region. The data have showed that the geodynamical evolution of structural-material complexes in the Archaean and the specific features of Early Precambrian volcanism could predetermine the original and unique composition of the products of later magmatism stages. It is concluded that metallogenic forecast based on the geodynamic reconstruction is a promising area of further research. This is especially important for Early Precambrian regions, since the authors described and justified a polycyclic and multistage mechanism of the Earth's crust enrichment in ore elements, which increases the concentration of useful components in ore deposits from ancient complexes to the young ones, both in the Phanerozoic Eon and in the Early Precambrian. This paper emphasizes that carbon schists of the Keivy domain can be rich in nanogold on an industrial scale and, together with aluminium raw materials, become a large auriferous province of the Kola region.
\end{abstract}

Keywords: evolution of the composition, Precambrian, geodynamic evolution, metallogeny.

\section{Введение}

Ранее авторы уже обращались к теме возможной связи поздних геологических событий с более ранними, показав, что формирование платинометальной и щелочной специализации региона могли определяться особенностями докембрийского магматизма (Козлов и др., 2005, 2017). Еще более очевидным является использование данных о геодинамических обстановках формирования раннедокембрийских структур непосредственно для прогноза их металлогении. Так, в своих предыдущих работах мы связывали, к примеру, известные повышенные концентрации молибдена (Виноградов, Балабонин, 1975) и золота (Гавриленко и др., 1987) с раннедокембрийской протоостроводужной историей Лапландского (Лапландско-Колвицкого) гранулитового пояса (Козлов, 2005). Анализ металлогенической специализации коллизионных зон (Сорохтин и др., 2017) позволяет предполагать формирование в его пределах повышенных концентраций, определявшихся раннедокембрийской геодинамикой формирования его протолитов, еще как минимум для титана, марганца, вана- 
дия, хрома, а также, возможно, меди, никеля и железа. Некоторые аспекты данной проблемы рассмотрены нами в ходе предыдущих исследований (Kozlov et al., 2018). Данной проблеме посвящена и настоящая работа.

\section{Методы и результаты}

Методика реконструкции геодинамических режимов формирования протолитов раннедокембраиских комплексов детально описана нами ранее (Козлов, Сорохтин и др., 2006; Kozlov et al., 2018). Нами были систематизированы материалы по геологии и вещественному составу раннедокембрийских комплексов. При этом показано, что принцип актуализма нельзя напрямую применять при изучении геодинамических обстановок докембрия в полной мере, без внесения каких-либо поправок, что должно учитываться при решении задач реконструкции докембрийских образований с использованием фанерозойских эталонов. Отметим, что в вопросах, касающихся металлогенического анализа, аналогичный вывод бал ранее сделан А.Д. Щегловым (1989).

В результате реконструкций было показано, что на ранних этапах становления супракрустальных комплексов Кольского региона был широко проявлен рассеянный рифтогенез в пределах древнейшей коры, имеющей, как минимум, черты континентальной. Возможно, реликты этой коры обнаружены в ядрах цирконов в ходе исследований последних десятилетий (Мыскова и др., 2005; Bayanova et al., 2016; Bridgwater et al., 1996). В ходе этого процесса были сформированы древнейшие комплексы Кейвской структуры.

Если результаты этих реконструкций геодинамических обстановок формирования протолитов раннедокембрийских структур региона сопоставить с данными о размещении в его пределах полезных ископаемых (рис. 1), последние находят более логичное объяснение. Как отмечено во введении, с протоостроводужной историей Лапландского (Лапландско-Колвицкого) гранулитового пояса мы связывали повышенные концентрации молибдена и золота (Козлов, 1995). Авторы понимают, что наличие в его повышенных концентраций этих элементов определялось всей его геологической историей, включая многостадийные метаморфические преобразования. Таким образом, говоря о возможной связи повышенных концентраций тех или иных элементов с ранней геодинамической историей Лапландско-Колвицкого гранулитового пояса, авторы рассматривают это как базовое предположение о возможных источниках рудного вещества, которое в каждом конкретном случае должно исследоваться дополнительно с учетом всех преобразований пород в пределах конкретных рудопроявлений.

Напомним, что с зонами субдукции, кроме отмеченных выше, связано формирование залежей многих других полезных ископаемых, таких как . Fe, Mn, Cu, Pb, Ag, Hg, Sn, Ge, Ti, W, Zn, Cd, Co, и др. (Сорохтин и др., 2017). Понятно, что не все из перечисленных элементов могли формировать повышенные концентрации в пределах данной структуры в эпоху раннедокембрийской протомагматической деятельности, формировавшей метавулканогенную часть ее разреза, также как сохраниться в ходе длительной метаморфической переработки пород, даже если они эти концентрации образовывали. Тем не менее, эту информацию целесообразно иметь в виду при проведении металлогенических прогнозов в пределах данной структуры.

По аналогии с этим можно связывать с геодинамикой формирования протолитов пород Колмозеро-Вороньинской зоны наличие уже известных в ее пределах повышенных концентраций золота, серебра, молибдена, свинца, цинка, бериллия, тантала и ниобия, меди, никеля и железа и более широко рассматривать ее металлогенические перспективы.

Процессы формирования осадочных глиноземистых гнейсов Кейвского массива также тесно ассоциируют с геодинамикой региона того времени. Напомним, что ранее нами высказывалось предположение о том, что Кейвы (как минимум, низы разреза этой структуры) являются самыми древними образованиями в регионе (Козлов и др., 2014). Этот вывод хорошо согласуется с геологоструктурными и геофизическими данными (Козлов, Сорохтин и др., 2006), согласно которым можно предположить, что Кейвский микроконтинент на определенном этапе геологического развития был погружен (притоплен) на некоторую глубину надвинувшимися на него более молодыми со- 


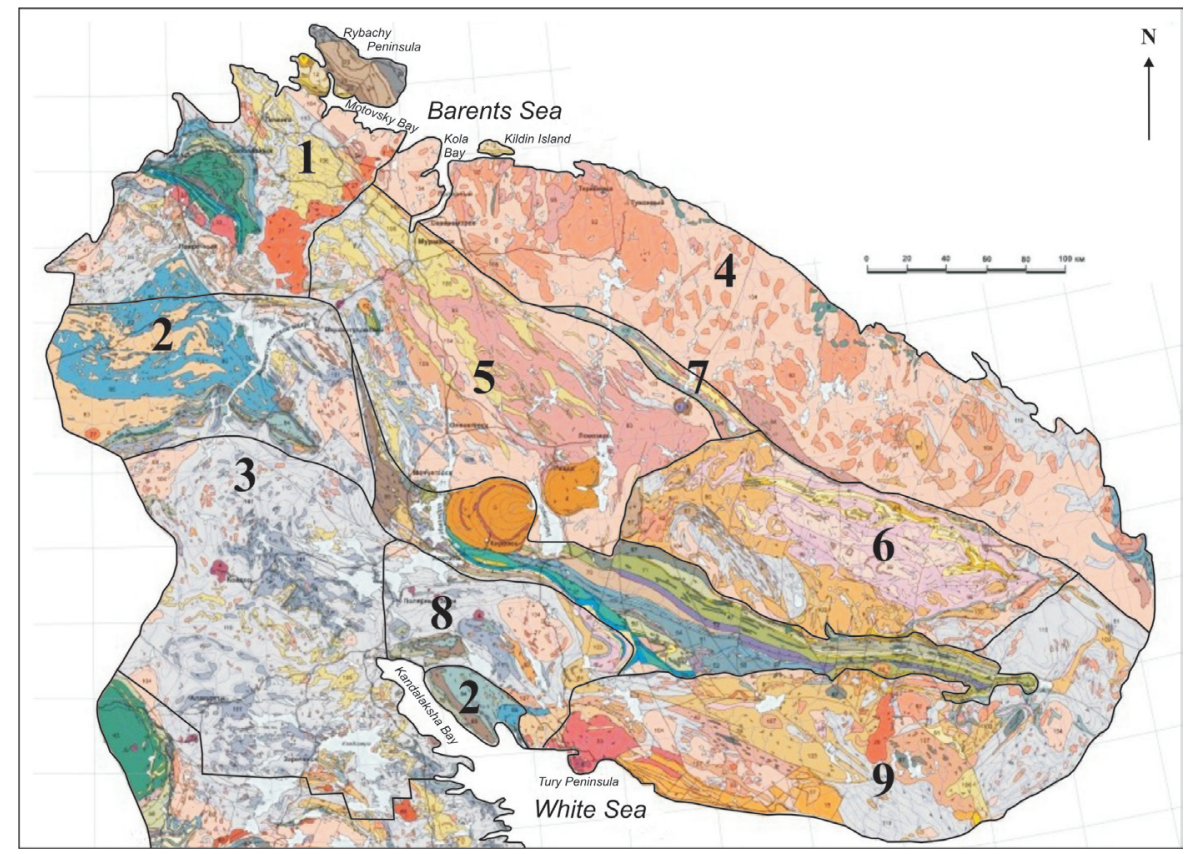

Рис. 1. Рудные районы Кольского региона (Пожиленко и др., 2002, с корректировками авторов).

1 - Печенгско-Аллареченский район (никель, медь, кобальт, сера, золото, серебро, платина, палладий, родий, рутений, иридий, селен, теллур, слюдоносные и керамические пегматиты); 2 - Лапландский рудный район (медь, никель, ванадий, титан, железо, марганец, молибден, графит и золото, хром, а также строительные и облицовочные материалы); 3 - Беломорский рудный район (месторождения мусковита и керамического сырья, сульфидное (Cu-Ni) и платинометалльное оруденение, сырье для алюминиевой промышленности); 4 - Мурманский рудный район (стройматериалы и облицовочный гранит, железистые кварциты и рудопроявления торий-уранового и уранового типа); 5 - Оленегорский рудный район (крупные месторождения железистых кварцитов, руды апатит-силикатные, апатит-магнетитовые ковдорского типа, апатит-карбонатные, тантало-ниобиевые, апатитовые и перовскит-титаномагнетитовые, строительные материалы); 6 - Кейвский рудный район (рудопроявления ниобия, тантала, циркония, иттрия, тория, урана, олова, вольфрама, ванадия и кобальта, крупные месторождения кианита, абразивного граната и амазонита, кварцитов, высококачественного жильного кварца, мусковита, силлиманита и т.д.); 7 - Колмозеро -Вороньинский рудный район (месторождения и проявления золота, серебра, молибдена, свинца, цинка, меди, никеля, железа, лития, бериллия, тантала, ниобийя, цезия); 8 - Кандалакшский рудный район (титано-магнетитовые и перовскито-титаномагнетитовые руды с редкими землями, фосфатное сырье, медная минерализация); 9 - Терский рудный район (крупные проявления мусковита и керамических пегматитов, декоративные красные песчаники, проявления молибденита, карбонатитов с апатитовой и редкометалльной минерализацией, барита, аметиста, проявления золота, находки алмазов).

Fig.1. Metallogenic areas of the Murmansk region (Pozhilenko et al., 2002, adjusted by authors).

1 - Pechenga-Allarechka area (nickel, copper, cobalt, sulphur, gold, silver, platinum, palladium, rhodium, ruthenium, iridium, selenium, tellurium, mica and ceramic pegmatites); 2 - Lapland ore area (copper, nickel, vanadium, titanium, iron, manganese, molybdenum, graphite and gold, chromium, construction and decorative materials); 3 - Belomorian ore area (deposits of muscovite and ceramic raw materials, sulfide $(\mathrm{Cu}-\mathrm{Ni})$ and Pt-bearing mineralization, raw materials for the aluminium industry); 4 - Murmansk ore area (construction and decorative granite, ferruginous quartzites and ore occurrences of the thorium-uranium and uranium type); 5 -Olenegorsk ore area (major deposits of ferruginous quartzites, apatite-silicate ores, apatite-magnetite ores of the Kovdor type, apatite-carbonate ores, tantalum-niobium ores, apatite and perovskite-titanium-magnetite ores, construction materials); 6 - Keyvy ore area (ore occurrences of niobium, tantalum, zirconium, yttrium, thorium, uranium, tin, wolfram, vanadium and cobalt, major deposits of kyanite, abrasive garnet and amazonite, quartzites, high-grade vein quartz, muscovite, sillimanite, etc.); 7 - Kolmozero-Voronya ore area (deposits and occurrences of gold, silver, molybdenum, lead, zinc, copper, nickel, iron, lithium, berillum, tantalum, niobium, caesium); 8 - Kandalaksha ore area (titanium-magnetite and perovskite-titanium-magnetite ores with rare earths, phosphate raw materials, copper mineralization); 9 - Tersky ore area (major occurrences of muscovite and ceramic pegmatites, decorative red sandstones, occurrences of molybdenite, carbonatites with apatite and rare metal mineralization, barite, amethyst, gold occurrences, diamond finds). 
седними континентальными массивами. После этого в неоархее, в ребольскую фазу складчатости, были сформированы опоясывающие эту структуру орогенные пояса. Это хорошо согласуется с выводом (Козлов и др., 1999), согласно которому юго-западная часть породных ассоциаций региона, начиная уже с архея, последовательно наращивала более древнее, расположенное на севере северо-востоке ядро (мезоархеское, возможно, палеоархейское).

Кора восточной части Кольского региона была в то время более мощной и зрелой, что определяло наличие здесь более глубинных магматических источников. Ландшафт сформированного на рубеже архея и раннего протерозоя срединного массива Кейв представлял собой равнину, окруженную со всех сторон высокими горными массивами. Возможно, поверхность Кейвского массива представляла собой мелководный бассейн, который формировался в приэкваториальной зоне. Это предположение следует из того, что в тот период времени на поверхности Земли был сформирован первый в ее истории суперконтинент (Моногея или Пангея-0), который по законам вращения Земли мог формироваться только вблизи экватора (Sorokhtin et al., 2011). Химический состав пород опоясывающих Кейвы горных систем был типичным для архейского времени. В большинстве своем это были тоналит-трондьемиты и гранодиориты, субщелочные базальтоиды, ультраосновные породы и анортозиты. Разрушаясь, они формировали целый ряд характерных осадочных комплексов, богатых алюминием и калием. Эти осадки накапливались в тектонически спокойных и, возможно, теплых лагунных условиях неоархейского климата.

В этой связи следует отметить, что геодинамическое положение срединного массива предполагает замкнутость процессов разрушения близлежащих орогенов, сноса материала на его поверхность, физико-химических минеральных преобразований и накопления осадочного чехла. Благодаря этому, по нашему мнению, в Кейвском срединном массиве были сформированы гигантские по объемам месторождения алюминевого сырья и широкие поля калиевого метасоматоза.

Одними из основных породообразующих минералов трондьемитов, тоналитов и гранодиоритов являются ортоклаз $\left(\mathrm{K}\left(\mathrm{AlSi}_{3} \mathrm{O}_{8}\right)\right)$, альбит $\left(\mathrm{Na}\left(\mathrm{AlSi}_{3} \mathrm{O}_{8}\right)\right)$, анортит $\left(\mathrm{Ca}\left(\mathrm{AlSi}_{2} \mathrm{O}_{8}\right)\right)$ и микроклин (полиморфная модификация ортоклаза), которые в присутствии воды разлагаются по реакциям типа:

$$
\begin{aligned}
& \mathrm{K}\left(\mathrm{AlSi}_{3} \mathrm{O}_{8}\right)+\mathrm{nH}_{2} \mathrm{O}+\mathrm{CO}_{2} \rightarrow \mathrm{Al}_{4}\left[\mathrm{Si}_{4} \mathrm{O}_{10}\right](\mathrm{OH})_{8}+\mathrm{K}_{2} \mathrm{CO}_{3}+\mathrm{SiO}_{2} * \mathrm{nH}_{2} \mathrm{O} \text {, } \\
& \text { ортоклаз каолинит поташ опал }
\end{aligned}
$$

или:

$$
\begin{aligned}
& 2 \mathrm{Ca}\left(\mathrm{AlSi}_{2} \mathrm{O}_{8}\right)+6 \mathrm{H}_{2} \mathrm{O} \rightarrow \mathrm{Al}_{4}\left[\mathrm{Si}_{4} \mathrm{O}_{10}\right](\mathrm{OH})_{8}+2 \mathrm{Ca}(\mathrm{OH})_{2} \\
& \text { анортит каолинит гидроксид кальция }
\end{aligned}
$$

и

$$
\underset{\text { альбит }}{\mathrm{Na}\left(\mathrm{AlSi}_{3} \mathrm{O}_{8}\right)}+\underset{22 \mathrm{H}_{2} \mathrm{O}}{2} \rightarrow \underset{4}{\mathrm{Al}_{4}\left[\mathrm{Si}_{4} \mathrm{O}_{10}\right](\mathrm{OH})_{8}}+\underset{\text { каолинит }}{4 \mathrm{NaOH}}+\underset{8 \mathrm{H}_{4} \mathrm{SiO}_{4} .}{\text { кремниевая кислота }}
$$

Также, в условиях гипергенеза и в теплом влажном климате, может происходить разложение ортоклаза на гидрослюдистые минералы, которые впоследствии образуют каолинит. Например:

$$
6 \mathrm{~K}\left(\mathrm{AlSi}_{3} \mathrm{O}_{8}\right)+2 \mathrm{CO}_{2}+2 \mathrm{H}_{2} \mathrm{O} \rightarrow 2 \mathrm{KAl}_{2}\left[\mathrm{AlSi}_{3} \mathrm{O}_{10}\right](\mathrm{OH})_{2}+2 \mathrm{~K}_{2} \mathrm{CO}_{3}+12 \mathrm{SiO}_{2} .
$$

В свою очередь, мусковит в присутствии углекислоты и воды может образовывать каолинит и карбонат калия по реакции:

$$
4 \mathrm{KAl}_{2}\left[\mathrm{AlSi}_{3} \mathrm{O}_{10}\right](\mathrm{OH})_{2}+2 \mathrm{CO}_{2}+8 \mathrm{H}_{2} \mathrm{O} \rightarrow \mathrm{Al}_{4}\left[\mathrm{Si}_{4} \mathrm{O}_{10}\right](\mathrm{OH})_{8}+2 \mathrm{~K}_{2} \mathrm{CO}_{3} .
$$

Дальнейшие процессы гидролиза, происходившие на рубеже архея и протерозоя в Кейвском домене в жарком и, возможно, влажном климате могли приводить к формированию латерита (красноцветный глинистый минерал) и оксида кремния:

$$
\mathrm{Al}_{4}\left[\mathrm{Si}_{4} \mathrm{O}_{10}\right](\mathrm{OH})_{8} \rightarrow \mathrm{H}_{2} \mathrm{Al}_{2} \mathrm{O}_{4}+\mathrm{SiO}_{2}+\mathrm{nH}_{2} \mathrm{O}
$$

или гидраргиллита и опала:

$$
\mathrm{Al}_{4}\left[\mathrm{Si}_{4} \mathrm{O}_{10}\right](\mathrm{OH})_{8} \rightarrow \mathrm{Al}(\mathrm{OH})_{3}+\mathrm{SiO}_{2}+\mathrm{nH}_{2} \mathrm{O} .
$$

При этом гидраргиллит содержит более $65 \%$ глинозема $\left(\mathrm{Al}_{2} \mathrm{O}_{3}\right)$. 
В дальнейшем, когда сформированный осадочный чехол Кейвского домена был перекрыт сверху более молодыми осадками и тектоническими надвиговыми пластинами обрамляющих орогенных структур Кольского региона, произошла дегидратация осадочного чехла, его прогрев и формирование знаменитых кианитовых сланцев. Этот процесс описывается простой эндотермической реакцией:

$$
\underset{\text { каолинит }}{\mathrm{Al}_{4}\left[\mathrm{Si}_{4} \mathrm{O}_{10}\right](\mathrm{OH})_{8}} \rightarrow \underset{2}{\mathrm{Al}_{2} \mathrm{OSiO}_{4}}+\underset{\text { кианит }}{2 \mathrm{H}_{2} \mathrm{O} .}
$$

Ее же можно записать еще более простым и понятным способом:

$$
\mathrm{Al}_{2} \mathrm{O}_{3} * 2 \mathrm{SiO}_{2} * 2 \mathrm{H}_{2} \mathrm{O} \rightarrow \mathrm{Al}_{2} \mathrm{O}_{3} * 2 \mathrm{SiO}_{2}+2 \mathrm{H}_{2} \mathrm{O}
$$

По нашему мнению именно так могли формироваться уникальные месторождения кианита в неоархее.

Кроме описанных выше процессов, следует обратить внимание на то, что разрушение и переотложение пород тоналит-трондьемитовой и гранодиоритовой серии сопровождалось образованием большого количества солей калия $\left(\mathrm{K}_{2} \mathrm{CO}_{3}\right)$. Эти соли хорошо растворимы в воде, поэтому, скорее всего, приводили к засолонению водонасыщенных осадочных толщ Кейвского домена того времени. Позже, в период их метаморфических преобразований калий послужил строительным материалом для формирования метасоматических микроклиновых (щелочных) гранитов, которые в избытке развиты по периферии домена.

Установленная нами принадлежность Кейвского домена к структурам, схожим по геодинамическим параметрам с фанерозойскими срединными массивами, например с Таримским, позволило Е.Н. Фоминой с соавторами (Fomina et al., 2019) на основании данных по изотопии углерода сделать вывод о возможности существования в осадочном чехле Кейвского террейна докембрийского нефтегазоносного бассейна. Это представляется логичным, однако следует учитывать, что за почти 3 млрд. лет высокоуглеродистые образования, естественно, были преобразованы в графит. Содержащаяся же в углеводородах того времени сера перешла в сульфиды. Таким образом, вся совокупность информации о геодинамической истории Кейвского домена может указывать на высокую вероятность находки в его пределах крупных залежей углеродистых сланцев, которые могут быть перспективны на обнаружение в них золота. Этот вывод следует из того, что раннепротерозойские углеводородные залежи имели бактериальную природу, накапливались в теплых и влажных условиях и могли являться концентраторами ряда металлов. Основная их часть со временем была окислена и вынесена гидротермальными потоками в результате наложения метаморфических процессов, а более инертное золото могло оставаться на месте и, образовывать тонкодисперсные вкрапления в графитовых сланцах. Пока, что это лишь предположение, которое требует дальнейшего и пристального изучения.

Более поздние образования - супракрустальные комплексы Кольско-Норвежского и Мурманского доменов, а также Беломорского подвижного пояса, формировались, как нам представляется, в условиях, более сходных с обстановками континентальных рифтов. Далее, при взаимодействии Беломорского домена с доменами, расположенными к северо-востоку от него шло формирование Лапландского протоостроводужного пояса (или, как минимум, метавулканитов нижней части его разреза - пород Тана-пояса), а при взаимодействии Кольско-Норвежского и Мурманского доменов - Колмозеро-Вороньинской шовной зоны, имеющей черты как островодужных, так и рифтогенных образований. Эти черты проявились и в составе метабазитов - в Лапландск-Колвицком поясе они в большей степени сходны с вулканитами юных дуг, в то время как в Титовско-Колмозерской шовной зон наблюдается сдвиг в направлении вулканитов срединно-океанических хребтов (Kozlov et al., 2018).

Можно также полагать, что формирование медно-никелевых рудопроявлений Лоттинского домена, известных в пределах Аллареченского района, обусловлены, в определенной мере, близостью его по геодинамических характеристикам формирования протолитов к трапповым формациям, известным подобной рудной специализацией. Относительно Кейвского домена следует отметить, 
что породы основного состава, имеющие сходство с магматическими образованиями трапповых формаций, развиты в его пределах крайне ограниченно и, скорее всего, не оказывали существенного влияния на его последующую металлогеническую специализацию. Более важными факторами, определявшими металлогению этого домена, была последующая переработка супракрустальных образований с образованием кор выветривания в период стабилизации (Предовский и др., 1980), а также с последующей региональной метасоматической переработкой (Козлов и др., 2017).

Образование железных руд в пределах Кольско-Норвежского домена также могло определяться его близостью по геодинамическим характеристикам к континентальным рифтогенным зонам, для которых характерна концентрация этого элемента. Напомним, что в юго-западной части домена широко развит мощный железокремнистый осадочно-вулканогенный комплекс, протягивающийся в северо-западном направлении вдоль границы его границы.

\section{Выводы}

Полученные в ходе настоящей работы данные о геодинамической эволюции структурновещественных комплексов Кольского региона в архейское время, в сочетании с информацией о том, что специфика вулканизма раннего докембрия могла предопределить своеобразие и уникальность состава продуктов последующих этапов магматизма, позволяют говорить о том, что металлогенический прогноз на основе геодинамических реконструкции представляется перспективным направлением дальнейших исследований. Это тем более важно для раннедокембрийских регионов, поскольку ранее авторами описан и обоснован полициклический и многоступенчатый механизм обогащения континентальной земной коры рудными элементами, который приводит к увеличению концентраций полезных компонентов в рудных залежах от древних комплексов к молодым как в фанерозое, так и в докембрии (Сорохтин и др., 2016,2017,2018). В качестве примера авторы подчеркивают, что углеродистые сланцы Кейвского домена могут быть обогащены нанозолотом в промышленных объемах и наряду с алюминиевым сырьем стать крупной золотоносной провинцией Кольского региона.

Работа выполнена в рамках тем государственного задания № 0226-2019-0052 и № 0149-2019-0005.

\section{Литература}

1. Виноградов Л.А., Балабонин Н.Л. Рудопроявления в породах гранулитовой серии западной части Кольского полуострова // Основные и ультраосновные породы Кольского полуострова и их металлогения. Апатиты: изд-во Кольского фил. АН СССР. 1975. С. 186-200.

2. Гавриленко Б.В., Басалаев А.А., Предовский А.А., Белолипецкий А.П., Болотов В.И., Мележик В.А., Федотов Ж.А., Козлов Н.Е. Фоновая золотоносность докембрийских осадочных и вулканических формаций Кольского региона // Геохимия. № 10. 1987. С. 1378-1385.

3. Козлов Н.Е. Вещественный состав метаморфических комплексов высокобарных гранулитовых поясов и проблема формирования их протолитов (на примере Лапландских гранулитов). Автореферат докторск. дисс. С-Пб. ИГГД. 1995. 36с.

4. Козлов Н.Е., Иванов А.А., Мартынов Е.В., Сорохтин Н.О., Козлова Н.Т. Сопоставление вещества архейских комплексов Мурманского домена и других архейских образований Балтийского щита, Гренландии и Канады // Доклады Академии наук. 2005. Т. 403. № 1. С. 75-77.

5. Козлов Н.Е., Мартынов Е.В., Сорохтин Н.О., Марчук Т.С. Эволюция вещественного состава метабазитов раннего докембрия Кольского региона. Вестник МГТУ. 2014. Т. 17. № 2. С. 304-313.

6. Козлов Н.Е., Мартынов Е.В.,Предовский А.А. Петрогеохимическая реконструкция природы метаморфических пород и геодинамических обстановок формирования их протолитов (новые подходы и ограничения) // Геология и геофизика. 1999. Т. 40. № 8. С. 1236-1244.

7. Козлов Н.Е., Сорохтин Н.О., Глазнев В.Н., Козлова Н.Е., Иванов А.А., Кудряшов Н.М., Мартынов Е.В., Тюремнов В.А., Матюшкин А.В., Осипенко Л.Г. Геология архея Балтийского щита. Спб. Изд-во: Наука. 2006. 329 c.

8. Козлов Н.Е., Фомина Е.Н.,Мартынов Е.В., Сорохтин Н.О., Марчук Т.А. О причине своеобразия состава пород Кейвского домена (Кольский полуостров) // Вестник МГТУ. 2017. Т. 20. № 1. С. 83-94. DOI: 10.21443/1560-9278-2017-20-1/1-83-94 (расширенная аннотация, подписи к рис. и табл - на английском).

9. Мыскова Т.А., Бережная Н.Г., Глебовицкий В.А., Милькевич Р.И., Лепехина Е.Н., Матуков Д.И., Антонов А.В., Сергеев С.А., Шулешко И.К. // Находки древнейших цирконов с возрастом 3600 млн. лет в гнейсах коль- 
ской серии Центрально-Кольского блока Балтийского щита (U-Pb, SHRIMP-II). ДАН. 2005. Т. 402. C. 82-86.

10. Пожиленко В.И., Гавриленко Б.В., Жиров Д.В., Жабин С.В. Геология рудных районов Мурманской области. Апатиты. Изд-во: КНЦ РАН. 2002. 359 с. (на русском языке).

11. Предовский А.А., Мележик В.А., Болотов В.И., Федотов Ж.А., Басалаев А.А., Козлов Н.Е., Иванов А.А., Жангуров А.А., Скуфьин П.К., Любцов В.В. Вулканизм и седиментогенез докембрия северо-востока Балтийского щита. Л. Изд-во: Наука. 1987. 185 с. (на русском языке).

12. Сорохтин Н.О., Лобковский Л.И., Козлов Н.Е. Металлогения зон субдукции // Вестник МГТУ. 2017. Т. 20. №. 1 C. 111-128. DOI: 10.21443/1560-9278-2017-20-1/1-111-128 (расширенная аннотация, подписи к рис. и табл - на английском).

13. Сорохтин Н.О., Лобковский Л.И., Новиков Г.В., Козлов Н.Е., Богданова О.Ю. Никифоров С.Л. Пространственно-временные закономерности проявления магматизма и гидротермальной деятельности в западной Арктике и северной Атлантике Океанология. 2016. Т. 56. № 4. С. 627-632.

14. Сорохтин Н.О., Лобковский Л.И., Козлов Н.Е. Закономерности рудогенеза зон субдукции Океанология. 2018 T. 58. № 1. С. 118-128.

15. Сорохтин Н.О., Лобковский Л.И., Козлов Н.Е. Металлогения зон субдукции // Вестник МГТУ. 2017. Т. 20. № 1. С. 111-128.

16. Щеглов А.Д. Современное сосостояние теоретических основ металлогении (препринт). Л. Изд-во: АН СССР. 1889. $22 \mathrm{c}$.

17. Bayanova T.B., Kunakkuzin E.L., Serov P.A., Fedotov D.A., Borisenko E.S., Elizarov D.V. and Larionov A.V. Precise U-Pb (ID-TIMS) and SHRIMP-II ages on single zircon and Nd-Sr signatures from Achaean TTG and high aluminum gneisses on the Fennoscandian Shield // 32nd Nordic Geological Winter Meeting, Helsinki, Finland, 13-15 January 2016. Abs. Spec. P. 172.

18. Bridgwater D., Scott D., Marker M., Balagansky V., Bushmin S., Alexejem N. LAM-ICP-MS ${ }^{207} \mathrm{~Pb} /{ }^{206} \mathrm{~Pb}$ ages from detrital zircons and the provenance of sediments in the Lapland-Kola belt // SVEKALAPKO Workshop. Lammi, Finland, 28-30.11.1996. Abstracts. Oulu University. 1996. P. 17.

19. Fomina E., Kozlov E., Lokhov K., Lokhova O., Bocharov V. Carbon Sources and the Graphitization of Carbonaceous Matter in Precambrian Rocks of the Keivy Terrane (Kola Peninsula, Russia) // Minerals. 2019. V. 9 (2). P. 94; https://doi.org/10.3390/min9020094.

20. Kozlov N.E., Sorokhtin N.O., Martynov E.V. Geodynamic Evolution and Metallogeny of Archaean Structural and Compositional Complexes in the Northwestern Russian Arctic // Minerals. 2018. V. 8(12). 573 pp.; https://doi.org/10.3390/min8120573.

21. Sorokhtin O.G., Chilingarian G.V., Sorokhtin N.O. Evolution of Earth and its climate. Elsevier Science. Developments in Earth and Environmental Sciences. 2011. V. 10. 763 pp. 